\title{
CHARACTERISATION OF MCP-7s MATERIAL FOR USE AS A BETA EXTREMITY DOSEMETER
}

\author{
M. Boschung $\dagger$, A. Homsy $\neq$ O. P. Joneja $\uparrow \neq$ and R. Chawla $\uparrow \ddagger$ \\ $\dagger$ Paul Scherrer Institute, CH-5232 Villigen, Switzerland \\ \$Ecole Polytechnique Federale de Lausanne \\ CH-1015 Lausanne, Switzerland
}

Received January 11 2000, in final revised form July 3 2000, accepted July 32000

\begin{abstract}
LiF:Mg,Cu,P phosphors (commercially designated as MCP-N) are very sensitive thermoluminescent detectors and are considered by many laboratories to hold great promise for low level radiation monitoring. It is their high efficiency relative to TLDs based on LiF:Mg,Ti which make MCP-N particularly attractive for low dose measurements. The currently investigated detector material made of $\mathrm{LiF}: \mathrm{Mg}, \mathrm{Cu}, \mathrm{P}$ bears the code name $\mathrm{MCP}-7 \mathrm{~s}$ and has a very thin active layer and consequently an improved response to low energy beta radiation. Detailed studies have been carried out to characterise MCP-7s detectors in terms of glow curve, beta and gamma response, reusability, batch homogeneity and fading. Based on the positive outcome of these investigations, the dosimetry service at PSI plans to replace the TL material LiF:Mg,Ti presently used for extremity dosimetry with MCP-7s.
\end{abstract}

\section{INTRODUCTION}

During the past few years, considerable efforts have been made to produce new thin detector materials for personal extremity dosimetry ${ }^{(1)}$. The understanding of how different physical parameters influence the characteristics of such materials has also been improved ${ }^{(2-5)}$. The main challenge has been to develop a TLD capable of measuring the personal dose equivalent at a depth of about $7 \mathrm{mg} \cdot \mathrm{cm}^{-2}$, without losing too much in sensitivity. Recently developed $\mathrm{LiF}: \mathrm{Mg}, \mathrm{Cu}, \mathrm{P}(\mathrm{MCP}-\mathrm{N})$ material has been reported ${ }^{(6)}$ to be considerably more sensitive than standard LiF:Mg,Ti. The performance and characteristics of LiF:Mg,Cu,P TLDs from Chinese (GR-200), Japanese and Russian manufacturers were investigated earlier ${ }^{(7-9)}$. The aim of the present work has been to study the characteristics of a new commercially available MCP-N TL material manufactured in Poland ${ }^{(10)}$, particularly with respect to the requirements laid down in the Swiss Dosimetry Ordinance ${ }^{(11)}$, and thus to qualify the material for use as a beta extremity dosemeter at the Paul Scherrer Institute (PSI). The investigations were carried out accordingly, i.e. such that sufficient information could be obtained concerning the parameters influencing the characteristics of the material when used in a routine manner. Detailed results from the entire experimental programme are documented separately ${ }^{(12)}$.

\section{DETECTOR SPECIFICATIONS AND EXPERIMENTAL PROCEDURES}

\section{TL detector material}

The detectors used in this study are discs $4.5 \mathrm{~mm}$ in diameter and $0.72 \mathrm{~mm}$ thick. Each disc consists of two parts, an active layer made of ${ }^{7} \mathrm{LiF}: \mathrm{Mg}, \mathrm{Cu}, \mathrm{P}$ with a thickness of about $0.03 \mathrm{~mm}$ and a non-active support base made of $\mathrm{LiF}$-carbon with a thickness of $0.69 \mathrm{~mm}$. The two parts were bonded together under pressure and at elevated temperature. These TLDs are manufactured in Poland under the code name MCP-7s. Annealing conditions recommended by the manufacturer are $240^{\circ} \mathrm{C}$ for 10 min, followed by a rapid cooling on a thick aluminium plate.

\section{Irradiation facilities}

The irradiations for the homogeneity, reusability, linearity and fading studies were carried out using ${ }^{137} \mathrm{Cs}$ gamma sources at the Institute of Applied Radiophysics (IRA, Switzerland) and at PSI. The beta irradiations for linearity, energy response and cover studies were performed at IRA with a ${ }^{90} \mathrm{Sr} /{ }^{90} \mathrm{Y}$ source and at Ris $\varnothing$ (Denmark) with ${ }^{90} \mathrm{Sr} /{ }^{90} \mathrm{Y},{ }^{85} \mathrm{Kr}$ and ${ }^{147} \mathrm{Pm}$ sources. For the gamma irradiations, the detectors were placed in a plastic support accommodating up to 100 TLDs. For the beta irradiations, the TLDs were placed in plastic holders with cover thicknesses of 6.5 and 10 mg.cm ${ }^{-2}$, respectively.

\section{Annealing and detector response}

Annealing of the detectors was done in a 'Venticell' oven manufactured by Medcentre $\mathrm{GmbH}$. The temperature is controlled electronically and can be varied from room temperature to $250^{\circ} \mathrm{C}$. From our own experience with these TLDs, we could confirm the recommendations of the manufacturer as regards annealing conditions, viz. a temperature of $240^{\circ} \mathrm{C}$ for $10 \mathrm{~min}$. During annealing, the TLDs were held in a $5 \mathrm{~mm}$ thick aluminium plate with the provision to insert a tiny ther- 
mocouple for on-line monitoring of the temperature. Rapid cooling to room temperature was achieved by quickly transferring the hot TLDs to an aluminium plate of $1.5 \mathrm{~cm}$ thickness maintained at room temperature.

All readings of the detectors were carried out by a computer controlled Harshaw 5500 TLD reader. No preheating was done. The heating rate of the nitrogen gas flow was $5^{\circ} \mathrm{C} . \mathrm{s}^{-1}$ for about $44 \mathrm{~s}$ to attain $240^{\circ} \mathrm{C}$. This temperature was kept constant for the rest of the readout cycle (about $36 \mathrm{~s}$ ). The signal representative of dose was taken as integral output over the complete period of 80 s. All TLDs were read out 4 days after irradiation, except those used for fading studies.

\section{EXPERIMENTAL STUDIES}

\section{Individual response and glow curve}

All 320 TLDs used in the present study (from the same batch of production) had never been used before. They were first subjected to an initialisation procedure consisting of three consecutive annealing and irradiation cycles. In order to assess the variability and spread of the responses of individual detectors, all TLDs were then irradiated with a gamma dose of $20 \mathrm{mSv}$ to determine their individual relative responses (i.e. normalised to the mean response). These individual relative responses were applied as a correction factor to subsequent raw detector measurements. The irradiation history of each TLD was recorded during the complete duration of the studies. Deconvolution of the glow curve was done using the Peak Fit ${ }^{\mathrm{TM}}{ }^{(13)}$ software and was based on first-order kinetics.

\section{Reusability of TLDs}

For assessing reusability, 114 detectors were selected from the complete batch of the initially used 320. This set was annealed, irradiated (with a $20 \mathrm{mSv}$ gamma radiation) and read out over three successive cycles. A second readout of the TLDs was made on each occasion to assess the residual dose. A smaller set of 20 TLDs was subjected to the readout process only, i.e. no additional annealing was applied. Several other smaller sets (of 10 TLDs each) were used to study the detector response at relatively low dose levels $(20 \mathrm{mSv})$ following irradiation to high doses ranging from $500 \mathrm{mSv}$ to $5 \mathrm{~Sv}$.

\section{Fading studies}

A fading study was carried out over a period of 6 weeks: 65 detectors were annealed simultaneously and irradiated to the same gamma dose $(20 \mathrm{mSv})$ in sets of 5 at 13 different times during the 6-week period. At the end of the 6 weeks, all the detectors were read out on the same day. For the thirteen sets of 5 detectors, the times elapsed between irradiation and read out were 0.5 ,
$1.25,2.5$, and 4.5 hours, 1,2 , and 4 days and $1,2,3$, 4,5 , and 6 weeks. The detectors were stored at room temperature between annealing, irradiation and readout.

\section{Linearity and beta energy dependence}

The linearity of the detector response was investigated using ${ }^{90} \mathrm{Sr} /{ }^{90} \mathrm{Y}$ beta and ${ }^{137} \mathrm{Cs}$ gamma sources. In both cases, the detectors were irradiated in the dose range of $1 \mathrm{mSv}$ to $5 \mathrm{~Sv}$. A subset of 10 TLDs was used for each dose level. The relative response for ${ }^{90} \mathrm{Sr} /{ }^{90} \mathrm{Y}$ $\left(\mathrm{E}_{\text {average }}=935 \mathrm{keV}\right),{ }^{85} \mathrm{Kr}\left(\mathrm{E}_{\text {average }}=251 \mathrm{keV}\right)$ and ${ }^{147} \mathrm{Pm}$ $\left(\mathrm{E}_{\text {average }}=62 \mathrm{keV}\right.$ ) beta sources (with respect to ${ }^{137} \mathrm{Cs}$ gammas) was also studied in conjunction with different cover material thicknesses.

\section{RESULTS AND DISCUSSION}

\section{Glow curves}

The glow curve of MCP-7s shown in Figure 1 consists of several overlapping glow peaks, namely three low temperature peaks (nos 1,2, and 3) in the range of approximately 407 to $465 \mathrm{~K}$, the main dosimetric peak (no 4) at approximately $511 \mathrm{~K}$, and no peak above 520 K. Figure 1 shows the measured glow curve superimposed on that of GR-200 material as reported by McKeever ${ }^{(14)}$. It can be seen that the maximum of luminescence emission occurs at the same temperature in both cases. The number of assessed peaks, however, differs. The MCP-7s glow curve shows no evidence for a local maximum above $520 \mathrm{~K}$, whereas three local maxima are observed between 400 and $480 \mathrm{~K}$. It should be mentioned that more recently reported GR-200 glow curves $^{(15,16)}$ indicate the same number of peaks as McKeever's results with, however, slightly lower temperature values.

The intensities of the individual glow peaks of MCP-7s, as obtained by computerised glow curve deconvolution (CGCD), relative to the sum of all peaks,

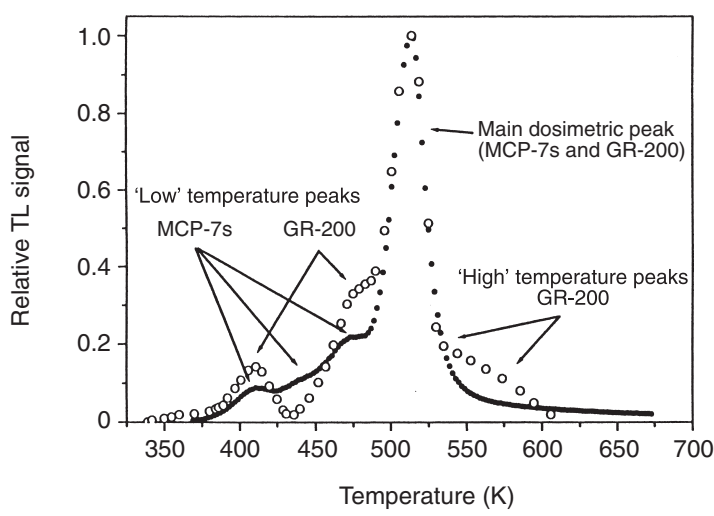

Figure 1. Glow curves of MCP-7s ( ) and GR-200A (O) TL materials. 
are presented in Table 1 for different experimental conditions.

\section{Response variation and reusability of TLDs}

As mentioned earlier, the individual response factor for each detector was obtained as its relative response with respect to the mean response of the entire batch of 320 TLDs used in the present studies. The standard deviation (SD) of the mean response was about $20 \%$, the relative response of a single detector being found to differ from the mean by up to more than $50 \%$. The magnitude of the individual response factors, and the effect on response variation of applying these factors, are shown in Figure 2 for the selected set of 114 TLDs. It can be seen that, on applying the individual response factors to subsequent readouts, the standard deviation of the mean drops to about $10 \%$. This figure is comparable to the batch homogeneity of $8 \%$ recently reported for

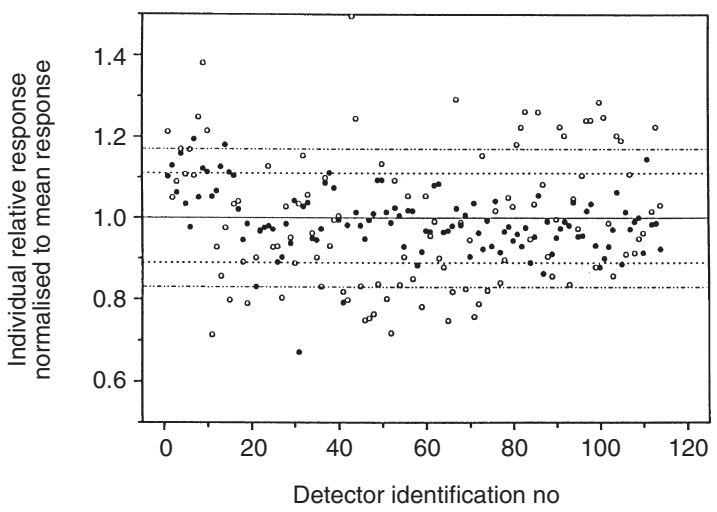

Figure 2. Raw $(\bigcirc)$ and corrected $(\bigcirc)$ relative responses of a subset of 114 MCP-7s normalised to the mean of the raw relative responses. The corrected responses were obtained using the individual response factors derived from an irradiation of the entire batch of 320 TLDs. SD raw data (-..-..-), SD corrected data (…..).
$\mathrm{MCP}-7 \mathrm{~s}^{(1)}$ as well as with the manufacturer's claim of $<9 \%$.

Figure 3 shows the evolution of the mean response of the 114 detectors over the four consecutive irradiation and readout cycles effectively employed for the reusability study. It is seen that, relative to the first reading, the change in the mean response over the three following cycles is less than $10 \%$. There is, however, some indication of a slight decrease. The standard deviation of the mean response of a given detector (over the four consecutive readouts) was found to be of the order of $5 \%$.

The residual TL signal, assessed by taking a second readout of the detector signal immediately after the first readout, was in all cases less than $4 \%$ of the first reading, the average value being about $1.7 \%$.

There was an increase in the individual response of about $10 \%$ when reader annealed only (instead of being annealed externally at $240^{\circ} \mathrm{C}$ for $10 \mathrm{~min}$ ). The computerised glow curve deconvolution results showed that, as compared to the results after the standard

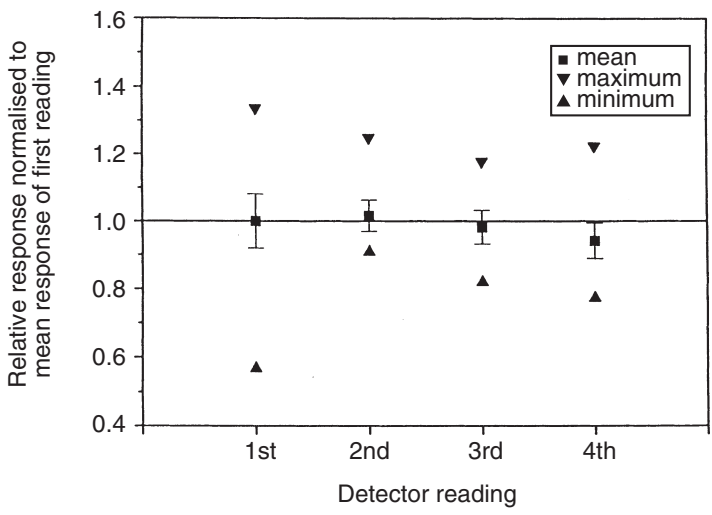

Figure 3. Stability of MCP-7s response as a function of the number of irradiation and readout cycles (results normalised to the first readout).

Table 1. Summary of MCP-7s glow peak intensities obtained by CGCD, relative to the sum of all peaks, for different experimental conditions (dose of $20 \mathrm{mSv}$ in each case).

Experimental conditions

Relative peak intensities at different temperatures

\begin{tabular}{llll}
\hline $413 \mathrm{k}$ & $445 \mathrm{k}$ & $476 \mathrm{k}$ & $510 \mathrm{k}$ \\
\hline
\end{tabular}

Gamma irradiation

1. Standard annealing and readout

0.04

0.07

2. Reader anneal only

3. Short fading ( $0.5 \mathrm{~h}$ between irradiation and readout)

4. High dose pre-irradiation

$\begin{array}{lll}0.07 & 0.19 & 0.70 \\ 0.07 & 0.30 & 0.56 \\ 0.19 & 0.11 & 0.64 \\ 0.11 & 0.17 & 0.69\end{array}$

Beta irradiation

1. Standard annealing and readout

0.03

0.09

0.19

0.69 
annealing procedure, peak nos 1 and 3 are more pronounced with respect to peak no 4 when only readeranneal is employed. This is similar to the behaviour of $\mathrm{LiF}: \mathrm{Mg}, \mathrm{Ti}$.

As regards the effects of high dose irradiation in the range $0.5-5.0 \mathrm{~Sv}$, it is seen from Table 2 that the observed changes in the TLD response were within the experimental errors.

\section{Fading}

Figure 4 shows the relative response normalised to the value corresponding to the shortest time interval, as a function of the elapsed time between irradiation and readout. An exponential curve was fitted to the data points to quantify the fading observations. According to this fitting curve, the detector response decreases by about $5 \%$ after 2 days. After 10 days, the decrease is about $10 \%$ and the response appears to be stable. An analysis of the computerised glow curve deconvolution results showed that peak nos 1 and 2 disappear completely after about 1 week. The fading characteristics could thus be improved significantly if an appropriate pre-heating is applied prior to the reading of the detectors, since this would substantially reduce the timedependent contribution arising from the low temperature peaks.

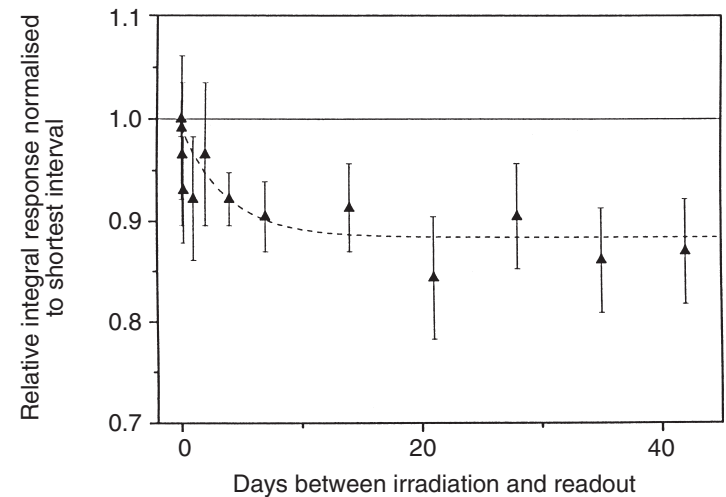

Figure 4. Fading study of MCP-7s over a period of 6 weeks. The responses are normalised to the value corresponding to the shortest time interval between irradiation and readout. The dotted line represents the fitted exponential function.

\section{Linearity}

Results for beta $\left({ }^{90} \mathrm{Sr} /{ }^{90} \mathrm{Y}\right)$ irradiated TLDs over the range of 1 to $500 \mathrm{mSv}$ (irradiation at IRA) were used to calculate a linearity relation between TL signal and dose (reference fit). Figure 5 shows, for each dose level in the total measured range of $1 \mathrm{mSv}$ to $5 \mathrm{~Sv}$ (including data obtained from irradiations made at Risø), the comparison of values calculated from the reference fit (C) and those directly obtained in the experiments (E).

In the case of ${ }^{137} \mathrm{Cs}$ gamma irradiations, a separate linear fit was made over the entire dose range $(1 \mathrm{mSv}$ to $5 \mathrm{~Sv}$ ). The goodness of this fit is also indicated in Figure 5.

\section{Beta response with different covers}

Table 3 shows the MCP-7s response for different cover thicknesses and different beta sources $\left({ }^{147} \mathrm{Pm}\right.$, ${ }^{85} \mathrm{Kr},{ }^{90} \mathrm{Sr} /{ }^{90} \mathrm{Y}$ ), comparison in each case being made to the ${ }^{137} \mathrm{Cs}$ gamma response. No significant cover-induced change was observed for the response to the ${ }^{90} \mathrm{Sr} /{ }^{90} \mathrm{Y}$ source, whereas the responses to ${ }^{85} \mathrm{Kr}$ and ${ }^{147} \mathrm{Pm}$ sources showed significant decreases. In the case of ${ }^{147} \mathrm{Pm}$, the decrease (with the $10.3 \mathrm{mg} . \mathrm{cm}^{-2}$ cover) was down to as little as $10 \%$ of the reference value. Clearly, in order to increase the response of the detector for such low beta energies, the cover thickness must be reduced considerably.

Table 3. Responses of MCP-7s for different beta irradiations and different covers, relative to the response to ${ }^{137} \mathrm{Cs}$ gammas. The uncertainties indicated are those specific to detector response and do not include the uncertainties (of about $5 \%$ ) in the reference dose values.

\begin{tabular}{lcc} 
Source & \multicolumn{2}{c}{ Response relative to ${ }^{137} \mathrm{Cs}$} \\
\cline { 2 - 3 } & $\begin{array}{c}\text { Cover } \\
\text { thickness } \\
6.5 \mathrm{mg} \cdot \mathrm{cm}^{-2}\end{array}$ & $\begin{array}{c}\text { Cover } \\
\text { thickness } \\
10.3 \mathrm{mg} \cdot \mathrm{cm}^{-2}\end{array}$ \\
\hline${ }^{137} \mathrm{Cs}$ & - & $1.00 \pm 4 \%$ \\
${ }^{90} \mathrm{Sr} /{ }^{90} \mathrm{Y}$ & $0.95 \pm 9 \%$ & $1.03 \pm 10 \%$ \\
${ }^{85} \mathrm{Kr}$ & $0.86 \pm 5 \%$ & - \\
${ }^{147} \mathrm{Pm}$ & & $0.09 \pm 5 \%$ \\
\hline
\end{tabular}

Table 2. Response of MCP-7s after a high dose irradiation, relative to its response before the irradiation.

TLD response

\begin{tabular}{lcccc}
\cline { 2 - 4 } & $0.5 \mathrm{~Sv}$ & $1 \mathrm{~Sv}$ & $3 \mathrm{~Sv}$ & $5 \mathrm{~Sv}$ \\
\hline after/before irradiation & $0.87 \pm 16 \%$ & $0.89 \pm 21 \%$ & $0.95 \pm 11 \%$ & $0.89 \pm 11 \%$ \\
\hline
\end{tabular}




\section{CHARACTERISATION OF MCP-7s MATERIAL}

\section{CONCLUSIONS}

Various characteristics of MCP-7s TLDs have been studied over a wide range of physical parameters. For the batch of TLDs considered, variation of response has been shown to be within about $10 \%$ when individual response factors are used for the TLDs. Reproducibility in the response of a given detector is about 5\%.

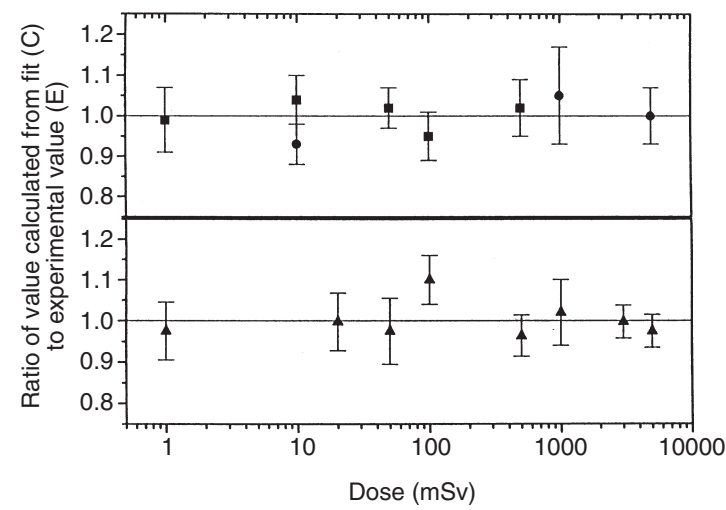

Figure 5. Linearity study of MCP-7s over the dose range of $1 \mathrm{mSv}$ to $5 \mathrm{~Sv}$. The experimental integral responses (E) are compared to values $(\mathrm{C})$ calculated from a linear fit. In the case of beta, the fit was based on measurements in the reduced range of 1 to $500 \mathrm{mSv}$. Upper part: beta (ם) IRA, () Ris $\emptyset$. Lower, gamma (A) PSI.
Linearity over the investigated dose range between 1 $\mathrm{mSv}$ and $5 \mathrm{~Sv}$ is found to be within about $5 \%$, for both beta and gamma radiation. The fading effect on the integral reading without preheating is about $10 \%$ during the first month. This is reduced to about 5\% if fading over the first 2 days after an irradiation is not considered. The energy response for betas with average energies down to $250 \mathrm{keV}\left({ }^{85} \mathrm{Kr}\right)$ does not differ by more than about $15 \%$ relative to the ${ }^{90} \mathrm{Sr} /{ }^{90} \mathrm{Y}$ response (with a cover of 6.5 $\mathrm{mg} . \mathrm{cm}^{-2}$ ). The lowest measurable dose (corresponding to three times the standard deviation of the background TL signal) is estimated to be $0.1 \mathrm{mSv}$.

The current investigations have demonstrated that MCP-7s satisfies the requirements stipulated in the Swiss Dosimetry Ordinance ${ }^{(11)}$ for beta extremity dosemeters. Thus, the various conditions for routine application in terms of lowest measurable dose, dose range, linearity, energy dependence, reproducibility and fading have been shown to be fullfilled, hence qualifying MCP-7s for use in beta extremity dosimetry at PSI.

\section{ACKNOWLEDGEMENTS}

The authors are grateful to C. Wernli, Head of the Metrology Section at PSI, for supporting this work. They are also grateful to staff members of the irradiation and standard laboratories at IRA, Risø and PSI for the personal help extended during the irradiation and calibration experiments.

\section{REFERENCES}

1. Moscovitch, M. Personal Dosimetry using LiF:Mg,Cu,P. Radiat. Prot. Dosim. 85, 49-56 (1999).

2. Stobe, T. G. and Chen, T. C. Role of Copper in Lif:Mg,Cu,P Thermoluminescent Phosphors. Radiat. Prot. Dosim. 78, 101106 (1998).

3. Kang, T., Cai, G., Shen, W., Min, L. and Zhu, H. An Improved LiF:Mg,Cu,P Chip With a Low Residual Signal. Radiat. Prot. Dosim. 84, 227-229 (1999)

4. Young-Mi Nam, Jang-Lyul Kim and Si-Young Chang. Dependence of Glow Curve Structure on the Concentration of Dopants in LiF:Mg, Cu,Na,Si Phosphor. Radiat. Prot. Dosim. 84, 231-234 (1999).

5. Ben-Amar, G., Ben-Shachar, B., Oster, L., Horowitz, Y. and Horowitz, A. Investigation of the Glow Peak Parameters, Reusability and Dosimetric Precision of LiF:Mg,Cu,P at High Heating Rates up to 20K.s ${ }^{-1}$. Radiat. Prot. Dosim. 84, 235238 (1999).

6. Bilski, P., Olko, P., Burgkhardt, B. and Piesch, E. Ultra-Thin LiF:Mg,Cu,P Detectors for Beta Dosimetry. Radiat. Meas. 24; 439-443 (1995).

7. Christensen, P. Study of LiF:Mg,Cu,P TL Detectors for Individual Monitoring for Weakly Penetrating Radiations. Radiat. Prot. Dosim. 47, 425-430 (1993).

8. Bilski, P., Budzanowski, M., Olko, P. and Christensen, P. Properties of Different Thin-Layer LiF:Mg,Cu,P TL Detectors for Beta Dosimetry. Radiat. Prot. Dosim. 66, 101-104 (1996).

9. Bacci, C., D'Angelo, L., Furetta, C. and Giancola, S. Comprehensive Study on LiF:Cu,Mg,P (GR-200A). Radiat. Prot. Dosim. 47, 215-218 (1993).

10. TLD Niewadomski \& Co, PL-30-545 Krakow.

11. Confoederatio Helvetica. Swiss Dosimetry Ordinance, SR 814.501.43, 7.10.1999.

12. Homsy, A. Characteristics of the New TL Material MCP-7s for Use as a Beta Extremity Dosimeter. Diplôme d'IngénieurPhysicien, EPFL (Février 1999).

13. PeakFitTM 4.0 (SPSS Science Inc., 444 N. Michigan Avenue, Chicago, IL, 60611, USA).

14. McKeever, J. et al. Properties of the Thermoluminescence Emission from LiF:Mg,Cu,P. Nucl. Tracks Radiat. Meas. 21, 179183 (1993). 
M. BOSCHUNG, A. HOMSY, O. P. JONEJA and R. CHAWLA

15. Oster, L., Horowitz, Y. S. and Horowitz, A. Further Studies of the Stability of LiF:Mg,Cu,P (GR-200) at Maximum Readout Temperatures Between $240^{\circ} \mathrm{C}$ and $280^{\circ} \mathrm{C}$. Radiat. Prot. Dosim. 65, 159-162 (1996).

16. Alves, J. G., Muñiz, J. L. and Delgado, A. On the Thermal Stability of LiF GR-200 in Environmental Exposures. Radiat. Prot. Dosim. 78, 107-111 (1998). 